\title{
Redesign of a BME Lab Class to Maintain Hands-on Experimentation Despite Remote Learning Constraints
}

\author{
David P. O’Neill (i) \\ Department of Biomedical Engineering, Northwestern University, Evanston, IL, USA \\ (Received 28 June 2020; accepted 25 October 2020; published online 10 November 2020)
}

\section{CHALLENGE STATEMENT}

The primary challenge was the redesign of a junioryear lab-based course, which ends a three-course sequence at a large private university, to function remotely while maintaining a hands-on experimental experience that would bring together skills developed in preceding courses of the sequence.

Course learning objectives included statistical design of experiments, understanding how to obtain a good measurement (sensor characterization, propagation of error, etc.), and good laboratory practice (record keeping, reporting, etc.). The synoptic nature of the laboratories is central to the ethos of the course, whereby students develop an appreciation for the whole experimental procedure: hypothesis generation, statistical design, equipment specification, building, characterization, data collection, analysis, interpretation, and reflection. By covering all of these aspects, students develop a feeling of ownership, and this engagement is typically highlighted in course feedback. The Spring 2020 enrollment was 49 students participating remotely from 7 different time zones spanning $16 \mathrm{~h}$, thus requiring asynchronous engagement. Further challenges arose from the university-wide change to $\mathrm{P} / \mathrm{F}$ grading and consequent impact upon student motivation.

Address correspondence to David P. O'Neill, Department of Biomedical Engineering, Northwestern University, Evanston, IL, USA. Electronic mail: david.oneill@northwestern.edu

\section{NOVEL INITIATIVE}

The novel initiative consisted of a multi-week laboratory project in the second half of the quarter, centered around implementing practical skills required to obtain and analyze good experimental data. The synoptic nature of the in-person course is considered valuable by both our students and their instructors of Senior Design as it demonstrates how skills and theory can be combined to conceive, implement, and analyze a full experimental investigation. Furthermore, Student-Equipment interactions ${ }^{1}$ are particularly valued by more advanced students. ${ }^{2}$ There are four pedagogical aspects to the novel initiative: course structure, equipment for remote labs, assessment, and social aspects to remote lab work.

\section{Course Structure}

Each week of the lab project had a different experimental focus but followed a similar structure. The first week had a preliminary lab exercise to build and characterize a sensor system. The second and third weeks focused upon instrumentation and signal processing respectively. In the fourth week the preceding work was brought together through inquiry-led human experimentation.

It was anticipated that the abrupt change halfway through the quarter from lectures and homework assignments to hands-on experimentation and documentation might be disruptive. A sensor-building and characterization lab activity developed by colleagues ${ }^{3}$ using the Physics Toolbox Suite ${ }^{4}$ and Galactica Lux Meter ${ }^{5}$ phone apps, was used as a transitioning experiential activity [S1]. Neither the equipment nor data from this session were required in the following weeks thus this created an opportunity for students to adjust 
to the change in instructor, TAs, pace, and assignment structure.

Subsequent lab activities were based around developing and using instrumentation and analysis code to determine mean arterial, systolic, and diastolic blood pressure through oscillometry. Foundational skills utilized included: statistical analysis (a prerequisite course and this course), instrumentation (a prerequisite course), signals and systems (a prerequisite course), and statistical design of experiments (first half of this course).

Due to time zones and scheduling constraints, written lab instructions were created for asynchronous activities. Students were asked to read the week's instructions the day before the nominal 'lab day' and to submit any muddy points ${ }^{6}$ to the instructor; anonymized responses were distributed to the whole class before the start of the 'lab day'. Muddy point completion rate was $>75 \%$. During the 'lab day', instructor availability (1 Faculty, 2 TAs) spanned 8 am to $6 \mathrm{pm}$ (campus time) through a continuous Zoom meeting. The faculty member remained available asynchronously via email after these hours. Follow-up ad hoc 60-min synchronous support sessions were offered on subsequent days through Zoom.

Instructions for the instrumentation-based lab activity (Week 2) were delivered in a worksheet format [S3]. This worksheet served as a useful instructional tool for checking student progress and understanding via Zoom or email. The analysis-based lab activity (Week 3) was code-focused, and instructions guided students through writing a full script. Code was not given, but students were directed to appropriate MATLAB/Python functions. Prompts were given for students to create various intermediary graphs and write reflective comments on what was observed. All students were supplied with a sample dataset that they could use for code development irrespective of whether or not their instrumentation from the prior week was working. Examples of intermediary graphs from analysis of the sample dataset were provided so that students could check their analysis scripts were performing satisfactorily.

For the final, inquiry-lead, human experimentation lab activity (Week 4), student teams were first tasked with creating a two-page research proposal [S4]. In preparation, students were introduced to the elements of a good hypothesis [S2] through a Zoom breakout room activity using PollEV. ${ }^{7}$ Power calculations had already been taught, practiced, and assessed in the first half of this course, and therefore students were explicitly permitted to explore hypotheses that may not be suitable given the small sample sizes achievable during COVID-19 restrictions.
In the final experimental activity, teams collected and analyzed data from themselves, family members, or house-mates to test their hypotheses.

\section{Equipment for Remote Labs}

In a preceding course, students had already been introduced to practical instrumentation through use of the nScope, ${ }^{8,9}$ a USB-powered oscilloscope/function generator to be used with a breadboard for instrumentation prototyping $(<\$ 100)$. The nScope also operates as a 4-channel DAQ with an open-source API and freeware applications for Windows, macOS, and Linux. Students were familiar with debugging using the oscilloscope application and with using Python for data collection. Additionally, a supply package was assembled and shipped to each student (Table 1; Fig. 1).

\section{Extended Lab Project Assessment}

Assessment of the multi-week laboratory project had three facets: an individual lab notebook (4 entries), a 2-page team research proposal, and a final team lab report.

The individual lab notebook entries were designed to incorporate best-practices of Standards-based Grading, ${ }^{13}$ developing record keeping skills through the lenses of instrumentation development, code development, and human data collection. There was an instructional focus on notebook completeness and reflective comments. Instructors routinely requested viewing of lab notebooks during zoom office hours and via asynchronous email support to determine lab progression, give feedback, and to demonstrate the utility of laboratory records in technical communication. Submissions were due immediately at the end of each asynchronous experimental work session.

The team lab report gave students a further opportunity for assessment of their technical writing, additionally assessing the student's refinement of the subject matter from the lab notebooks (e.g., selecting what content should be included in, or omitted from, this more formal written format).

\section{Social Interaction Through Team Membership and Breakout Sessions}

Rotation of team membership was a much-appreciated element of the in-person course, not least because students discovered with whom they were able to form strong (or poor) working relationships ahead of team-formation in Senior Design. In this course offering, unique teams were formed for the preliminary laboratory exercise and multi-week project. Addition- 
TABLE 1. Details of contents of supply package shipped to students; the sphygmomanometer was selected to have: a manual hand pump and release valve, separate tubing for pump and manometer, and a removable manometer.

\begin{tabular}{|c|c|c|c|c|c|c|}
\hline Description & Quantity & OEM & Product & Supplier & Cost & References \\
\hline Consumer-grade blood pressure cuff & 1 & Medvice & $\begin{array}{l}\text { Aneroid sphygmomanome- } \\
\text { ter }\end{array}$ & Amazon & $\$ 21$ & 10 \\
\hline $\begin{array}{l}\text { Board-mountable (DIP) } 5 \text { psi gage pressure } \\
\text { sensor }\end{array}$ & 1 & Honeywell & TBPDANS005PGUCV & Mouser & $\$ 10.63$ & 11 \\
\hline Instrumentation amplifier & 2 & $\begin{array}{l}\text { Analog De- } \\
\text { vices }\end{array}$ & AD623ANZ & Mouser & $\$ 4.40$ & 12 \\
\hline Miscellaneous electronics spares & $\mathrm{N} / \mathrm{A}$ & N/A & $\begin{array}{l}\text { Resistors, capacitors, wire, } \\
\text { LEDs }\end{array}$ & $\begin{array}{l}\text { Stock sup- } \\
\text { plies }\end{array}$ & $<\$ 5$ & $\mathrm{~N} / \mathrm{A}$ \\
\hline $\begin{array}{l}\text { nScope for students that left theirs on } \\
\text { campus }\end{array}$ & 1 & nScope & $\mathrm{N} / \mathrm{A}$ & nScope & $\$ 89$ & 9 \\
\hline
\end{tabular}

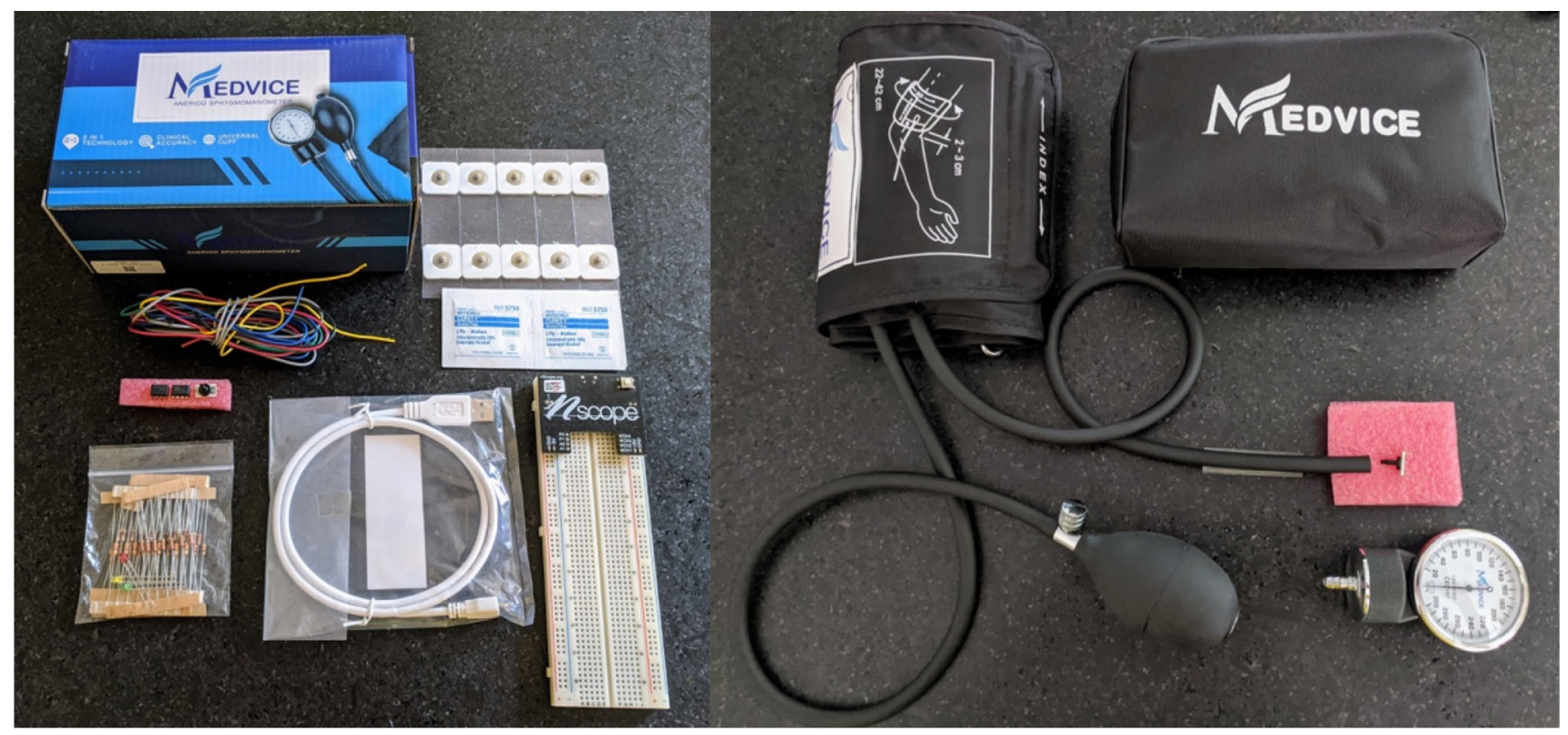

FIGURE 1. Left: contents of shipment sent to each student including: consumer blood pressure cuff, nScope (for students that left theirs on campus), board-mountable gage pressure sensor, and miscellaneous electronics spare parts. Right: unpackaged blood pressure cuff with manometer detached and board-mountable pressure sensor ready for attachment to cuff tubing.

ally, students were randomly distributed for any synchronous Zoom breakout sessions throughout the course.

To promote social interactions, breakout sessions $(\sim 5$ students) were scheduled to run slightly longer than required to complete the breakout activity. Students were instructed to start with icebreakers [S5] before completing the exercise. They were informed that the exercise should be completed with $\sim 5 \mathrm{~min}$ remaining which could be used for social chat of any form. Students were encouraged, but not required, to turn on front-facing laptop cameras for breakout sessions.

\section{REFLECTION}

Course evaluations showed no statistically significant difference from 2019's evaluations for either the course or the instruction provided by the author. An anonymous post-grades survey $(n=31$ out of 49 students responding) provided additional data. Most questions used a 5-point bipolar Likert scale, with optional free-text responses for responders to add qualifiers or additional feedback.

\section{Course Structure}

Most students (42/49) used synchronous office hours or email for support. The majority of survey 
responders (20/31) reported having adequate support available (Fig. 2). Anecdotally, students reported feeling slightly overwhelmed by the $12-15$ pages of combined lab instructions and worksheets; in response, a 20-min lab-overview video was created to assist comprehension.

The supplied sample dataset proved a useful instructional tool for remote code debugging, and also enabled students to progress even if their own data were poor. It was observed that some students struggled with navigating or interpreting coding help-page documentation. In the future, supplementary walkthrough videos will be created to assist with this.

Tip: multimodal delivery (notes, videos, muddy points, discussion boards) is potentially even more valued in a remote-learning environment.

\section{Equipment for Remote Labs}

Equipment selection was largely successful; there were no reported issues beyond international shipping delays. The student-designed differential amplifier stage was not universally appropriate for the pressure sensor because of mismatched output/input impedances. This required a short-notice pivot, with an instructional video on input/output impedance, buffers, and the instrumentation amplifier. This designredesign step proved serendipitous as a teaching tool and will be incorporated into future course offerings, albeit structured so as to maximize the "Learn from Failure",14 learning opportunity.

Students reported that they appreciated the effort to maintain the hands-on nature of the lab course in a remote setting but commented on the difficulty of remote debugging; this remains an area for further development. Students found the bringing together of instrumentation, signal analysis, and experimentation a helpful culminating experience (Fig. 3), vindicating the prioritization of a synoptic experiential lab project.

Professor [...] making the effort to mailing out or drop off circuit part packages we [sic] huge. The final lab we did at the end of the quarter, building a blood pressure monitor, was definitely very engaging and fun.

..doing nScope work with remote instruction is difficult. Not the course's fault

The use of circuitry to measure BP was the most engaging part of this course. I felt like my [preceding course] knowledge was being culminated as well as some of the physio[logy] sequence.
In the blood pressure lab project I felt I had adequate support available through synchronous 10 zoom office hours/lab support and emails with the Professor and/or TAs:

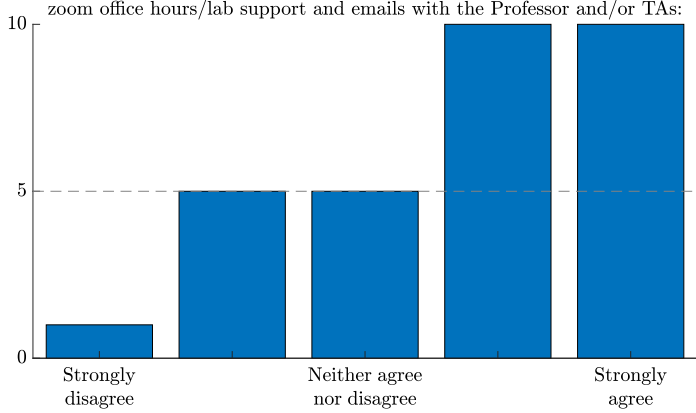

FIGURE 2. Student survey response about degree of instructional support for labwork.

The blood pressure lab brought together elements of BME305/6/7 in the bigger picture of BME experimentation. I found this a

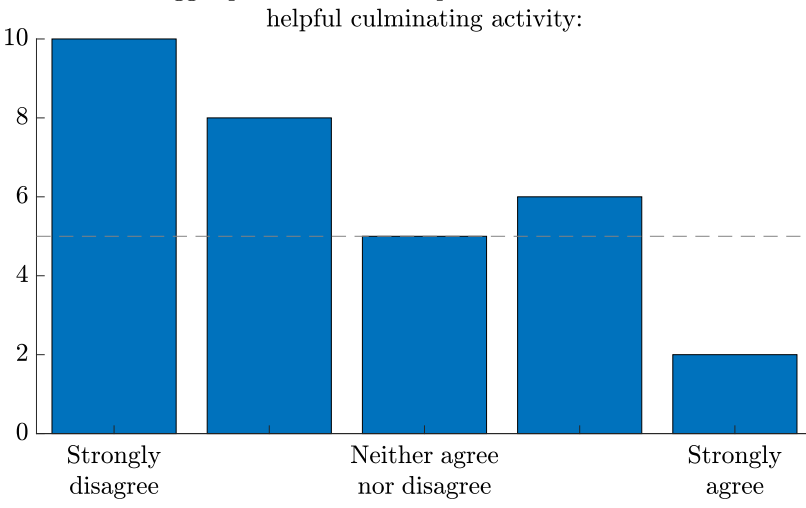

FIGURE 3. Student survey response about the lab project being a helpful culminating activity for the experimental course sequence.

\section{Extended Lab Project Assessment}

Instructors found the combination of worksheets and lab notes particularly helpful for remote 'debugging'. Anecdotally, students commented that including experimental 'failures' in their notes was useful in describing problems to instructors during both synchronous and asynchronous support.

Students' understanding about what constitutes appropriate and faithful lab records was initially overestimated: lab notebook scores (Fig. 4) for the first week were statistically lower than for subsequent weeks $(P<0.001$; Cohen's $d=2.4)$. However, this suggests that initial formative feedback ${ }^{15,16}$ was successful at addressing this.

The intraclass correlation coefficient $\left(\operatorname{ICC}(3,1)^{17}\right)$ for notebook scores \#2-4 was 0.16, which was not significantly different from zero. This indicates substantial intrasubject variability in performance across notebook assessments after initial formative feedback. Each of these assignments reflected a different technical laboratory focus, from which we infer that indi- 

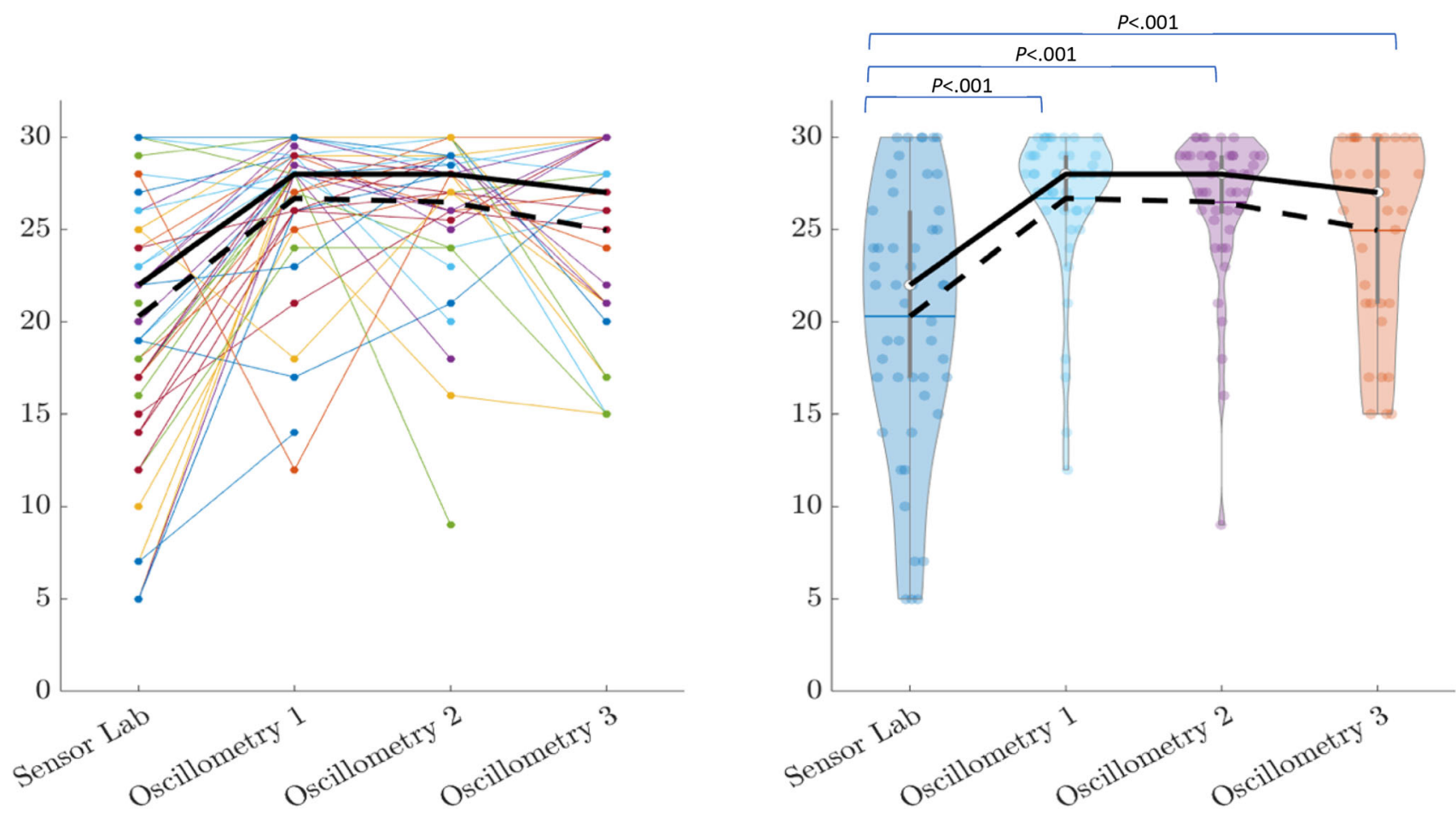

FIGURE 4. Left: Raw scores for lab notebook submission assignments. 14 students elected to omit or only partially complete the last assignment in the wake of the parent institution declaring final assessments be made optional in response to events following the murder of George Floyd on May 25th, 2020. Right: Violin plot of lab notebook scores for each experimental week; medians, interquartile ranges, and means are shown. Statistically significant differences between the initial 'Sensor Lab' and other assignments suggests some combination of successful formative feedback and overestimation of student understanding about what constitutes good faithful lab records. Both plots: thick black line denotes assignment median score; thick dashed line denotes assignment mean score. Across Oscillometry Lab notebook assignments $1-3$, the ICC $(3,1)^{17}$ was 0.16 (not significant).

vidual students' technical strengths and weaknesses permeate through to their record-keeping proficiency in that content area. Future evaluation of formative assessment methods should account for variations in assignment focus.

Students commented that it "kept things interesting" to practice lab record-keeping skills on different types of experimental work. Students reported that grading lab notes with a rubric that evaluated faithful record keeping rather than experimental success 'decreased stress levels a lot' and 'increased motivation to learn a little' (Fig. 5).

Tip: consider uncoupling assessment of lab completion and technical writing, e.g., record keeping.

\section{Social Interaction Through Team Membership and Breakout Sessions}

Numbers were not recorded, but instructors and TAs estimated $>90 \%$ of students used their frontfacing cameras in breakout room sessions. Anecdotally, students reported feeling more socially isolated than if there had been in-person classes. Most agreed that efforts described above helped them feel less socially isolated (Fig. 6 upper panel) and increased their motivation to learn (Fig. 6 lower panel). Notably, these reflections have a mode of Likert point 4, suggesting social isolation was mitigated but not resolved.

Learning remotely decreased my motivation to learn as much, but I think working in groups made me feel more accountable for my work, as my teammates were also dependent on my work.

Responses were less clear over students' desire to have socially interactive learning activities if it necessitated more class time (Fig. 7).

\section{Archiving Old Class Experimental Data}

The first half of this course is not the focus of this article, but one serendipitous event is worth noting. By chance, instructors had access to full datasets of platereader absorbency results from student-led inquiry experiments ${ }^{18}$ from previous course offerings. This archive of diverse hypotheses and corresponding da- 
The structure of lab submissions (lab notes were graded for *faithful record keeping* rather than *experimental success*; lab worksheets/code/sensor values were not graded) was helpful for motivation and stress:

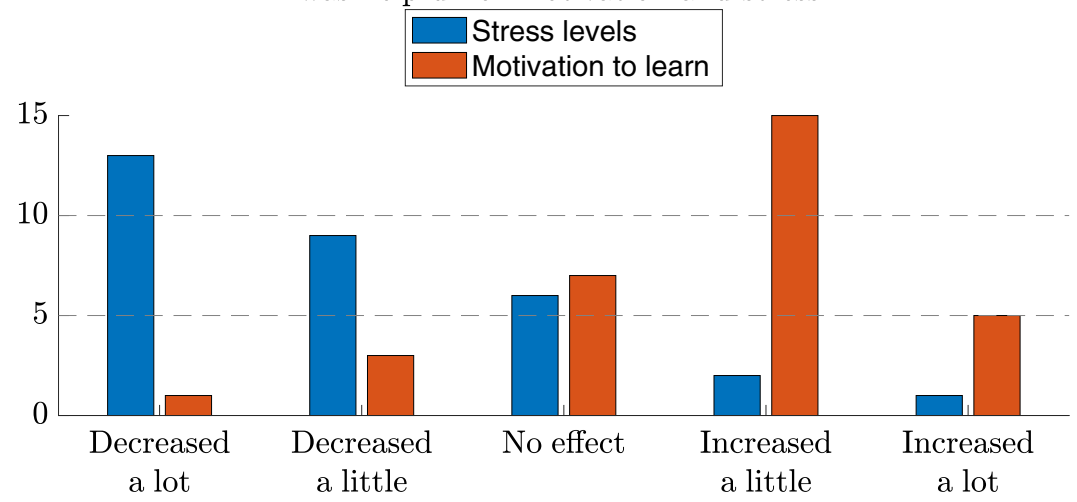

FIGURE 5. Student survey response to the effects of the structure of lab submissions on student motivation and self-perceived stress levels.

Zoom breakout-room sessions helped me feel less socially isolated Team project work in BME307 helped me feel less socially isolated

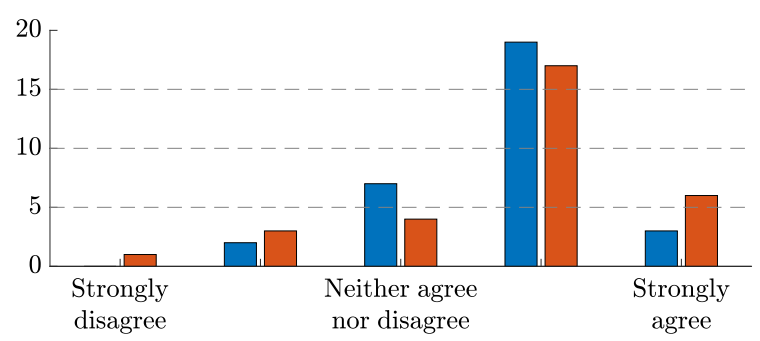

Compared to having exclusively individual work, team project work and Zoom breakout-room sessions increased my motivation to learn in BME307: 20

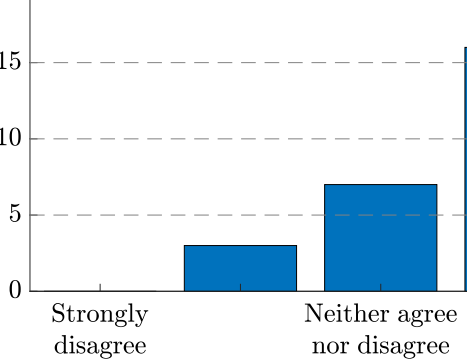

FIGURE 6. Student survey response to the impact of Zoom breakout-room sessions and team project work on feelings of social isolation (upper panel), and on motivation to learn (lower panel).

tasets was presented for analysis, offering some feeling of an inquiry-led activity.

We intend to create a departmental-wide repository of course-based experimental data.

Tip: archive experimental data even if there is no expectation to use it.
Particularly in remote learning, having interactive learning activities in synchronous sessions often means less content can be delivered. As a result, more class time would be needed to achieve the same learning objectives:

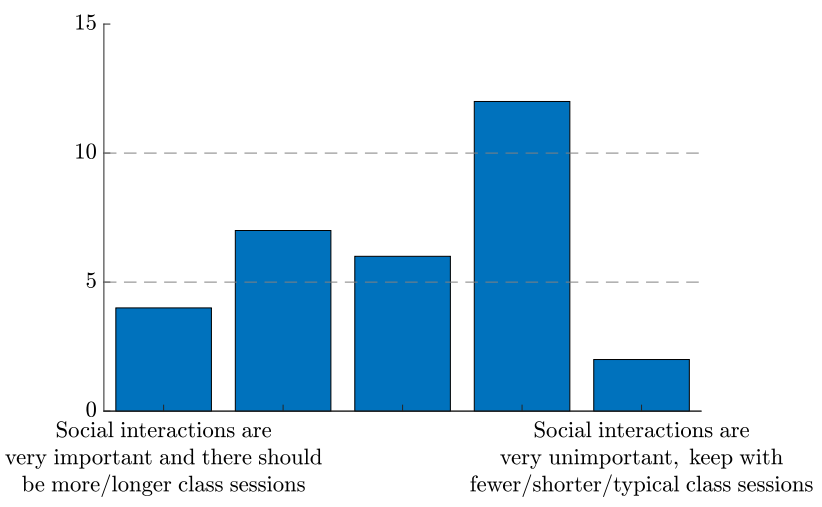

FIGURE 7. Student survey response to balancing levels of socially interactive learning with total amount of required class time.

\section{ELECTRONIC SUPPLEMENTARY MATERIAL}

The online version of this article (https://doi.org/10. 1007/s43683-020-00039-4) contains supplementary material, which is available to authorized users.

\section{ACKNOWLEDGEMENTS}

The author wishes to thank: M.G. Bright, C.J. Ankeny, M.C. Tresch, G. Fitch, S.A. Olds, L. Golestani Rad, and N. Marchuk, for thoughtful discussion and advice, C. Drennon and M. Okun Perlin for administrative assistance, and A. Dragunas and V. Goyal for instructional support. 


\section{CONFLICTS OF INTEREST}

The author declares that he has no conflict of interest.

\section{CONSENT TO PARTICIPATE}

$\mathrm{N} / \mathrm{A}$ : not deemed human research by IRB.

\section{CONSENT FOR PUBLICATION}

N/A: not deemed human research by IRB.

\section{AUTHOR CONTRIBUTIONS}

DPO'N conceived the article, collected and analyzed data.

\section{FUNDING}

Not applicable.

\section{AVAILABILITY OF DATA AND MATERIAL}

Survey data and anonymized grades available on request.

\section{REFERENCES}

\footnotetext{
${ }^{1}$ Anderson T. Getting the mix right again: an updated and theoretical rationale for interaction. Int Rev Res Open Distance Learn. 2003. https://doi.org/10.19173/irrodl.v4i2. 149.

${ }^{2}$ Lal S, Lucey AD, Lindsay ED, Treagust DF, Mocerino M, Zadnik MG. A study of the relative importance of student interactions for the attainment of laboratory-learning outcomes. In: AAEE, Brisbane. 2019.
}

${ }^{3}$ Ankeny CJ, Tresch MC. Creation and deployment of a virtual, inquiry-guided biomedical engineering laboratory course. Biomed Eng Educ. 2020. https://doi.org/10.1007/ s43683-020-00017-w.

${ }^{4}$ Physics Toolbox Sensor Suite. https://play.google.com/ store/apps/details?id = com.chrystianvieyra. physicstoolbox suite\&hl=en_US. Accessed 23 June 2020.

${ }^{5}$ Galactica Luxmeter. https://apps.apple.com/us/app/galact ica-luxmeter/id666846635.Accessed 23 June 2020.

${ }^{6}$ Carberry A, Krause S, Ankeny C, Waters C. 'Unmuddying' course content using muddiest point reflections. IEEE Front Eng Educ. 2013.

${ }^{7}$ PollEV. pollev.com. Accessed 20 June 2020.

${ }^{8}$ Loftus M. Lab in a box. ASEE Prism. 2019;29(2):33-5.

${ }^{9}$ nscope. https://www.nscope.org/. Accessed 23 June 2020.

${ }^{10}$ Amazon. www.amazon.com/Medvice-Manual-Blood-Press ure-Cuff/dp/B0848K8XJH. Accessed 20 June 2020.

${ }^{11}$ Honewell Sensing. https://sensing.honeywell.com/TBPDA NS005PGUCV-unamplified-board-mount-pressure-sensors. Accessed 20 June 2020.

${ }^{12}$ Analog Devices. https://www.analog.com/media/en/techni cal-documentation/data-sheets/AD623.pdf. Accessed 20 June 2020.

${ }^{13}$ Carberry AR, Siniawski M, Atwood SA, Diefes-Dux HA. Best practices for using standards-based grading in engineering courses. In: ASEE, New Orleans. 2016.

${ }^{14}$ Feisel LD, Rosa AJ. The role of the laboratory in undergraduate engineering education. $J$ Eng Educ. 2005;91(1):121-30.

${ }^{15}$ Black P, Wiliam D. Developing the theory of formative assessment. Educ Assess Eval Account. 2009;21:5.

${ }^{16}$ Isobel Rolfe JM. Formative assessment: how am I doing? Lancet. 1995;345(8953):837-9.

${ }^{17}$ Salarian A. Intraclass correlation coefficient (ICC), MATLAB central file exchange. https://www.mathworks.com/ matlabcentral/fileexchange/22099-intraclass-correlation-co efficient-icc. Accessed 23 June 2020.

${ }^{18}$ Adams B, Jorgensen S, Arce-Trigatti A, Arce P. Innovative curriculum design for enhancing learning in engineering education: the strategies, principles, and challenges of an inquiry-guided laboratory. In: INTED. 2020.

Publisher's Note Publisher's Note Springer Nature remains neutral with regard to jurisdictional claims in published maps and institutional affiliations. 